\title{
Design of Human Non-Pancreatic Secretary Phospholipase A2 (hnps-PLA2) Inhibitors: A Structure Based Molecule Design Approach
}

\author{
Amit Nagal \\ Advanced Bioinformatics Center \\ Birla Institute of Scientific Research, \\ Statue Circle, Jaipur \\ India
}

\section{Introduction}

Phospholipase A2 (PLA2) catalyzes the hydrolysis of the SN-2 acyl ester linkage of phospholipids and producing fatty acids and lysophospholipids. Their activity is one of the rate-limiting steps in the formation of arachidonic acid and in the synthesis of leukotrienes and prostaglandins. These prostaglandins have vital role in carcinogenesis. In the present study structure based drug design approach has applied to the hnps-PLA2 inhibitors. It can be concluded that indole-3-acetamide derivative molecule $13 \mathrm{~h}$ was showing better interaction with the active site of hnps-PLA2. The comparative in silico ADME studies proved that $13 \mathrm{~h}$ molecule could be a potential anticancer drug. Phospholipase is an enzyme that converts phospholipids into fatty acid and other lipophillic-substances. There are four major classes of Phospholipase, termed A, B, C and D. These classes are distinguished by the catalyzing type of reactions. Phospholipase A has two subtypes: Phospholipase A1 which cleaves the SN-1 acyl chain and Phospholipase A2 which cleaves the SN-2 acyl chain.

\section{Material and method}

Ligand fit (Discovery studio 2.1) software was used for molecular docking studies (Venkatachalam, C.M. et al. 2003). It is based on a cavity detection algorithm and Monte Carlo conformational search algorithm for generating ligand poses consistent with the active site shape. The crystal structure of hnps-PLA2 (1DB4) complex with potent indole inhibitor was determined and used in structure based drug design (Schevitz RW et al 1995). The PDB structure 1DB4 was chosen for our study has $2.20 \mathrm{~A}^{\circ}$ resolution and has RMSD value below $2 \mathrm{~A}^{\circ}$.

\subsection{Ligand and receptor preparation}

The hnps-PLA2 inhibitors, 74 indole-3-acetic acid derivatives (Robert D. Dillard et al 1996) were sketched. The structure of all molecules used in the present study was designed on the 
basis of the reported scaffold and the substituent table from NCBI pubchem. The Generic drugs with diverse scaffolds were downloaded from pubchem library. The Hydrogen Bonds were added and CHARMm force field was applied to all molecules.

The crystal structure of hnps-PLA2 protein (1DB4) was downloaded from the PDB. After applying CHARMm force field macro molecule hnps-PLA2 was assigned as receptor. The receptor cavity was searched using flood filling algorithm and partition site was adjusted for the better fitments of molecule in the partition site of receptor. The comparative docking studies for all 100 molecules were performed. The determination of the ligand binding affinity was calculated using Ligscore1, Ligscore2 and Dock score were used to estimate the ligand-binding energies.In the present study ADME Tox software was used to study the toxicity of hnps-PLA2 inhibitors. We have used top ten ranked dock molecule of hnps-PLA2 for the present study.The Hydrogen Bonds were added and CHARMm force field was applied to all molecules and the ADME properties were calculated.

\section{Result and analysis}

In the present study we have taken generic drugs with diverse scaffolds and indole inhibitors of hnps- PLA2 which were biologically tested and synthesized (Robert D. Dillard et al 1996). The structure based studies of the molecules described above were carried out using Discovery Studio. The RMSD value between the top ten ranked (based on docked energy) reference molecules and hnp-SPLA2 was reported around $2 \mathrm{~A}^{\circ}$.

Table 1 had shown the different score values of top ranked ligands against hnsp-SPLA2 receptor. The score values include Ligscore1 and Ligscore 2 which is based on proteinligand affinity energy (Krammer et al 2005). It has been observed that Ligscore1 (6.16), Ligscore2 (7.06) were found highest for the $13 \mathrm{~h}$ molecule in comparison with the other 100 molecules. During the study it has been observed that molecule $13 \mathrm{~h}$ which was found highest docked energy score 80.47 has high inhibitory concentration (IC50 .03 uM) which proved that the drugs found most effective in prior experimental studies was also giving high dock scores.

It has been reported that indole inhibitors when substituted with additional alkyl group at different positions of indole the efficacy of the compound had increased towards hnps-PLA2 (Lin et al 2003). In the present study the molecules having indole ring proved more efficient when substituting with other additional groups on indole ring. In comparison with the binding affinity of the other molecules it has been observed that indole-3- derivatives were found most effective scaffold. The top 7 Ranked docked molecules had indole ring and a additional acid side chain on the fifth position with acid group (13h $(80.47 \mathrm{~J} / \mathrm{mol}), 41(71.59$ $\mathrm{J} / \mathrm{mol}), 2 \mathrm{n}(70.59 \mathrm{~J} / \mathrm{mol}), 71(70.48 \mathrm{~J} / \mathrm{mol}), 7 \mathrm{i}(68.14 \mathrm{~J} / \mathrm{mol}), 16 \mathrm{~b}(67.71 \mathrm{~J} / \mathrm{mol}), 60 \mathrm{a}(67.71$ $\mathrm{J} / \mathrm{mol}$ ) ) It has been observed that indole-3-acetamides series molecule possessed potency and selectivity as inhibitors of hnps-PLA2 (Robert D. Dillard et al 1996). It was observed that the top 6 docked molecules (molecule $13 \mathrm{~h}(80.47 \mathrm{~J} / \mathrm{mol}), 41(71.59 \mathrm{~J} / \mathrm{mol}), 71(70.48 \mathrm{~J} / \mathrm{mol})$, $7 \mathrm{i}(68.14 \mathrm{~J} / \mathrm{mol}), 16 \mathrm{~b}(67.71 \mathrm{~J} / \mathrm{mol}), 60 \mathrm{a}(67.71 \mathrm{~J} / \mathrm{mol}))$ had 3-acetamide side chain at Indole ring. The molecule $13 \mathrm{~h}$ had oxy propyl phosphonic acid group on fifth position which had shown strong hydrogen bonding formation with the active site residue histidine of hnpSPLA2 receptor.(Fig 1). 


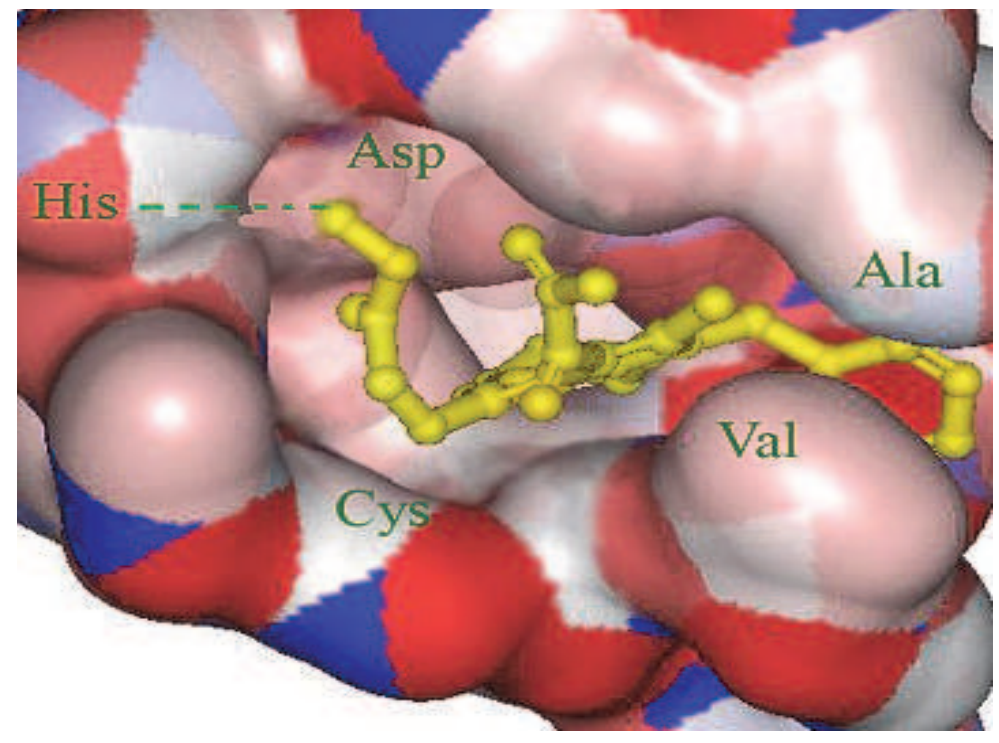

Fig. 1. Molecule 13h showing hydrogen bonding with histidine 


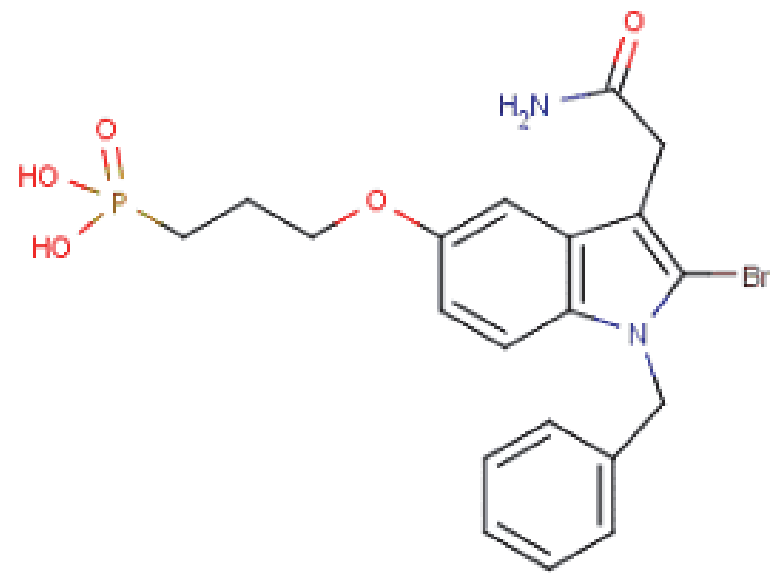

Fig. 2. Molecule 13h 


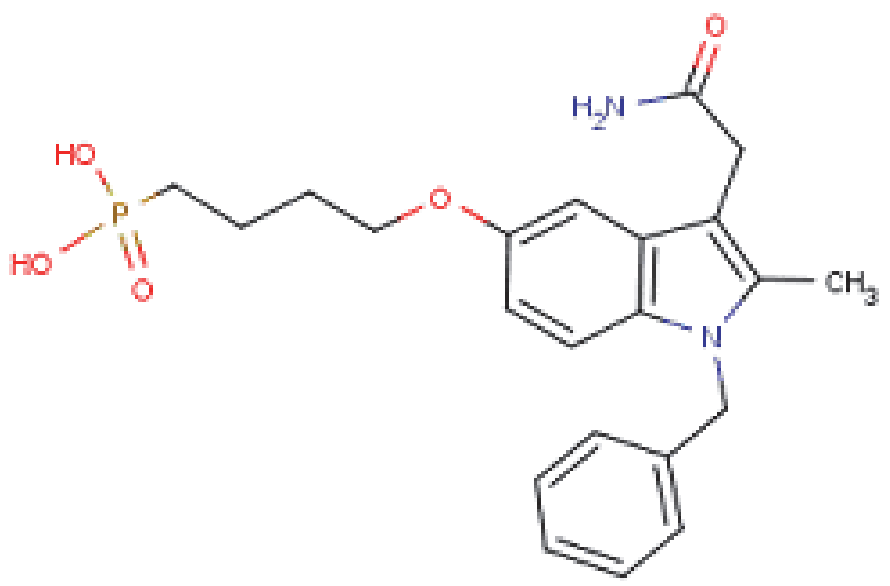

Fig. 3. Molecule 41 showing similarties with mol 13h

The structural similarity of two top ranked dock score molecules suggested that both had 3-indole acetamide ring as basic scaffold and phosphonic acid group which was attached to fifth position of indole and a benzyl ring which was attached to first position of indole.(Fig 2,3)

The top ten ranked dock molecules were chosen for ADME analysis. The ADME properties of $13 \mathrm{~h}$ were found very satisfactory. The aqueous solubility value was found within optimal range-(4.028) whereas the molecule indomethcin (3.24), indoprofen (3.54) was found not good solubility value. The molecule 16b, 7i, 71, 60a had poor (3) intestinal absorption level whereas molecule $13 \mathrm{~h}$ had very good (0) intestinal absorption level. The Plasma protein binding was found more than $90 \%$ for molecule $13 \mathrm{~h}$ but it was reported more than $95 \%$ for 
the molecule 41 and 2n. The Blood Brain Penetration Level for molecule $13 \mathrm{~h}$ was found to be extremely low (4) level and the cytochrome P450 enzyme (1) level was not found to be inhibited by molecule $13 \mathrm{~h}$. Thus comparing with the other molecules ADME properties $13 \mathrm{~h}$ had a good therapeutic index.

\begin{tabular}{|c|c|c|c|}
\hline Name & LigScore1 & LigScore2 & DOCK_SCORE \\
\hline $13 \mathrm{~h}$ & 6.16 & 7.06 & 80.47 \\
\hline Bendazac & 2.79 & 2.97 & 71.766 \\
\hline 41 & 6 & 6.62 & 71.496 \\
\hline $2 \mathrm{n}$ & 3.33 & 2.89 & 70.596 \\
\hline 71 & 5.64 & 6.39 & 70.48 \\
\hline $7 \mathrm{i}$ & 6.14 & 6.27 & 68.147 \\
\hline $16 \mathrm{~b}$ & 4.27 & 5.19 & 67.71 \\
\hline $60 \mathrm{a}$ & 4.88 & 6.63 & 67.487 \\
\hline Indometacin & 3.54 & 4.26 & 66.921 \\
\hline Indoprofen & 2.86 & 2.85 & 66.375 \\
\hline $13 \mathrm{f}$ & 5.81 & 6.9 & 65.9 \\
\hline $4 \mathrm{n}$ & 4.76 & 5.46 & 65.728 \\
\hline $7 \mathrm{o}$ & 5.47 & 5.84 & 65.64 \\
\hline $7 \mathrm{r}$ & 5.32 & 6.4 & 65.526 \\
\hline
\end{tabular}

Table 1. Sketched molecules with Best dock score

\section{Conclusion}

In the present study it can be concluded that Indole derivative molecule $13 \mathrm{~h}$ is proved to better molecule in terms of experimental studies, molecular interaction with hnp-SPLA2 receptor and computational ADME studies. So the present study proved that hnps-PLA2 
based inhibitor molecule $13 \mathrm{~h}$ (Fig 4) could be a better substitute for NSAID (Non-steroid anti inflammatory drug).
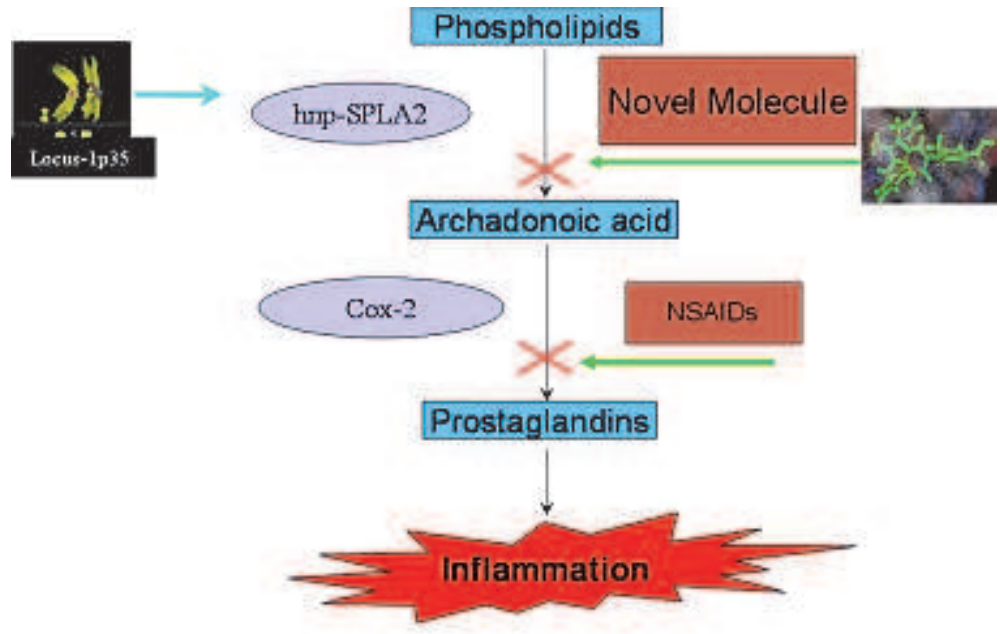

Fig. 4. Showing alternate pathway for inflammation

\section{References}

Robert D. Dillard \& Nicholas. (1996). Indole Inhibitors of Human Nonpancreatic Secretory Phospholipase A2. Indole-3-acetamides with Additional Functionality. J. Med. Chem, Vol 39, pp. 5137-5158.

Robert D. Dillard \& Nicholas. (1996). Indole Inhibitors of Human Nonpancreatic Secretory Phospholipase A2. Indole-3-acetamides. J. Med. Chem, Vol.39, pp. 5119-5136.

Lars Linderoth \& Thomas L. (2008). Molecular Basis of Phospholipase $\mathrm{A}_{2}$ Activity toward Phospholipids with sn-1 Substitutions. Biophys J. Vol 94, pp. 14-26

Venkatachalam CM \& Jiang.(2003) LigandFit: A Novel Method for the Shape-Directed Rapid Docking of Ligands to Protein Active Sites.J Mol Graph Modell, Vol 21, pp. 289-307. 
Krammer A \& Kirchhoff PD. (2005) LigScore: a novel scoring function for predicting binding affinities. J Mol Graph Model, Vol 23, pp. 395-407.

Schevitz RW \& Bach NJ. (1995). Structure-based design of the first potent and selective inhibitor of human non-pancreatic secretory phospholipase A2. Nat Struct Biol., Vol 2, pp .458-65. 


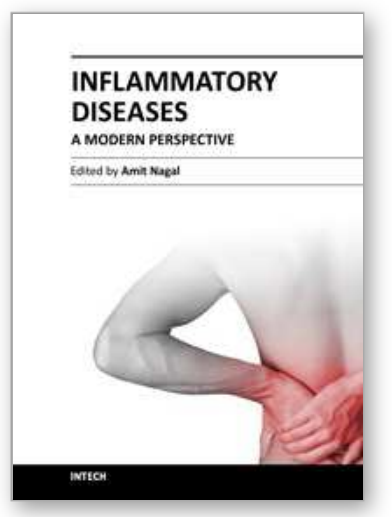

\author{
Inflammatory Diseases - A Modern Perspective \\ Edited by Dr. Amit Nagal
}

ISBN 978-953-307-444-3

Hard cover, 240 pages

Publisher InTech

Published online 16, December, 2011

Published in print edition December, 2011

"Inflammatory Diseases - A Modern Perspective" represents an extended and thoroughly revised collection of papers on inflammation. This book explores a wide range of topics relevant to inflammation and inflammatory diseases while its main objective is to help in understanding the molecular mechanism and a concrete review of inflammation. One of the interesting things about this book is its diversity in topics which include pharmacology, medicine, rational drug design, microbiology and biochemistry. Each topic focuses on inflammation and its related disease thus giving a unique platform which integrates all the useful information regarding inflammation.

\title{
How to reference
}

In order to correctly reference this scholarly work, feel free to copy and paste the following:

Amit Nagal (2011). Design of Human Non-Pancreatic Secretary Phospholipase A2 (hnps-PLA2) Inhibitors: A Structure Based Molecule Design Approach, Inflammatory Diseases - A Modern Perspective, Dr. Amit Nagal (Ed.), ISBN: 978-953-307-444-3, InTech, Available from: http://www.intechopen.com/books/inflammatorydiseases-a-modern-perspective/design-of-human-non-pancreatic-secretary-phospholipase-a2-hnps-pla2inhibitors-a-structure-based-mol

\section{INTECH}

open science | open minds

\section{InTech Europe}

University Campus STeP Ri

Slavka Krautzeka 83/A

51000 Rijeka, Croatia

Phone: +385 (51) 770447

Fax: +385 (51) 686166

www.intechopen.com

\section{InTech China}

Unit 405, Office Block, Hotel Equatorial Shanghai

No.65, Yan An Road (West), Shanghai, 200040, China

中国上海市延安西路65号上海国际贵都大饭店办公楼 405 单元

Phone: +86-21-62489820

Fax: $+86-21-62489821$ 
(C) 2011 The Author(s). Licensee IntechOpen. This is an open access article distributed under the terms of the Creative Commons Attribution 3.0 License, which permits unrestricted use, distribution, and reproduction in any medium, provided the original work is properly cited. 